Supplement of

\title{
Argon offline-AMS source apportionment of organic aerosol over yearly cycles for an urban, rural, and marine site in northern Europe
}

\section{Carlo Bozzetti et al.}

Correspondence to: André S. H. Prévôt (andre.prevot@psi.ch) and Imad El Haddad (imad.el-haddad@psi.ch)

The copyright of individual parts of the supplement might differ from the CC-BY 3.0 licence. 


\section{EC:hopanes ratio}

2 The EC:hopanes ratio was calculated considering the sum of the four most abundant

3 measured hopanes $(17 \mathrm{a}(\mathrm{H}), 21 \mathrm{~b}(\mathrm{H})$-norhopane, 17a(H),21b(H)-hopane, 22S, 17a $(\mathrm{H}), 21 \mathrm{~b}(\mathrm{H})$ -

4 homohopane, and 22R,17a(H),21b(H)-homohopane (hopanes sum $_{\text {) }}$ ). These four hopanes were

5 also the most abundant in the TEOA profiles used in this study to determine the TEOA

6 concentration (He et al., 2006; He et al., 2008; El Haddad et al., 2009; and Fraser et al., 1998).

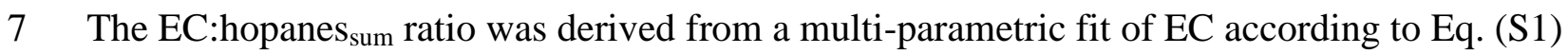

$$
E C=a \cdot B B O C+b \cdot h o p a n e s
$$

where $a$ represents $\mathrm{EC}: \mathrm{BBOC}$ and $b$ represents the EC:hopanes sum ratio. $a$ was constrained to 0.39 which is the average EC:BBOC ratio determined from the markers source apportionment.
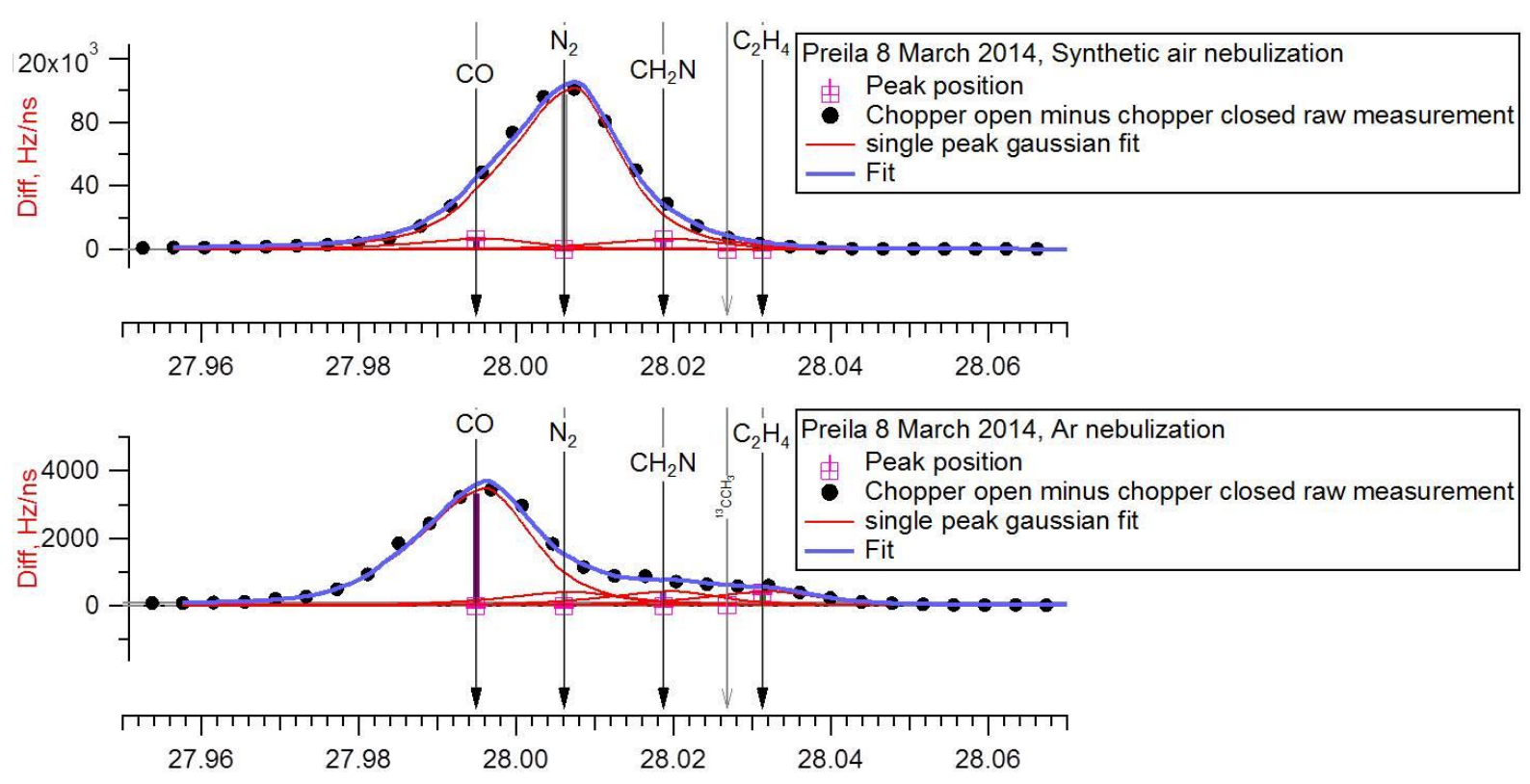

Figure S1. $m / z$ 28: HR fit of the chopper open minus closed spectrum (Diff). Top plot: nebulization performed in Ar, bottom plot: nebulization performed in synthetic air.

Table S1: measured compounds.

\section{Compounds class}

(as in table 1)

\section{Measured compounds}

Filters

measured

$$
\text { Ions } \quad \mathrm{SO}_{4}^{2-}, \mathrm{NO}_{3}^{-}, \mathrm{Cl}^{-}, \mathrm{NH}_{4}^{+}, \mathrm{Na}^{+}, \mathrm{K}^{+}, \mathrm{Ca}^{2+}, \mathrm{Mg}^{2+} \text {, oxalate, }
$$


Phenanthrene, anthracene, fluoranthene, pyrene,

benzo[a]anthracene, chrysene, triphenylene, retene,

PAHs

benzo[b,k]fluoranthene, benzo[j]fluoranthene, 67 composite

benzo-e-pyrene, benzo[a]pyrene, indeno[1,2,3 - samples

cd]pyrene, dibenzo[a,h]anthracene, benzo[ghi]perylene, coronene

dibenzothiophene, phenanthro(4,5-bcd)thiophene,

Benzo(b)naphtho(2,1-d)thiophene,

Benzo(b)naphtha(1,2-d)thiophene

S-PAHs

Benzo(b)naphtho(2,3-d)thiophene, Dinaphtho(2,1-

b;1',2'-d)thiophene, Benzo(b)phenantho(2,1-

d)thiophene

Me-PAHs

2-methylnaphtalene, 1-methylfluoranthene, 3-

methylphenanthrene, 2-methylphenanthrene, 2-

methylanthracene, 4/9 methylphenanthrene, 1-

methylphenanthrene, 4-methylpyrene, 1-

methylpyrene, 1+3-methylfluoranthene,

methylfluoranthene/pyrene, 3-methylchrysene,

methylchrysene/benzoanthracene.

Trisnorneohopane,

$17 \mathrm{a}(\mathrm{H})$-trisnorhopane,

17a(H),21b(H)-norhopane,

$17 \mathrm{a}(\mathrm{H}), 21 \mathrm{~b}(\mathrm{H})$-hopane,

Hopanes

22S, 17a(H),21b(H)-homohopane,

22R, 17a(H),21b(H)-homohopane,

22S, 17a(H),21b(H)-bishomohopane,

22R, 17a(H),21b(H)-bishomohopane, 
22S, 17a $(\mathrm{H}), 21 \mathrm{~b}(\mathrm{H})$-trishomohopane,

22R, 17a $(\mathrm{H}), 21 \mathrm{~b}(\mathrm{H})$-trishomohopane,

vanillin, vanillic acid, acetovanilone, guaiacyl

acetone, coniferyl aldehyde, homovanilic acid,

Methoxyphenols syringol, 4-methylsyringol, 4-propenylsyringol, acetosyringone, syringyl acetone, sinapyl aldehyde, syringic acid,

Others

Cholesterol, 6,10,14-trimethyl-2-pentadecanone

Sugar alcohols

Arabitol, sorbitol, mannitol

Anhydrous sugars

Levoglucosan, mannosan, galactosan

Monosaccharides

Glucose

Undecane (C11), dodecane (C12), tridecane (C13), tetradecane $(\mathrm{C} 14)$, pentadecane $(\mathrm{C} 15)$, exadecane (C16), heptadecane (C17), octadecane (C18), nonadecane (C19), eicosane (C20), heneicosane (C21), docosane (C22), tricosane (C23), tetracosane (C24), pentacosane (C25), hexacosane (C26),

Alkanes heptacosane (C27), octacosane (C28), nonacosane (C29), triacontane (C30), untricontane (C31), totriacontane (C32), tritriacontane (C33), tetratriacontane (C34), pentatriacontane (C35), hexatriacontane (C36), heptatriacontane (C37), octatriacontane (C38), nonatriacontane (C39), tetracontane (C40), pristane, phytane 

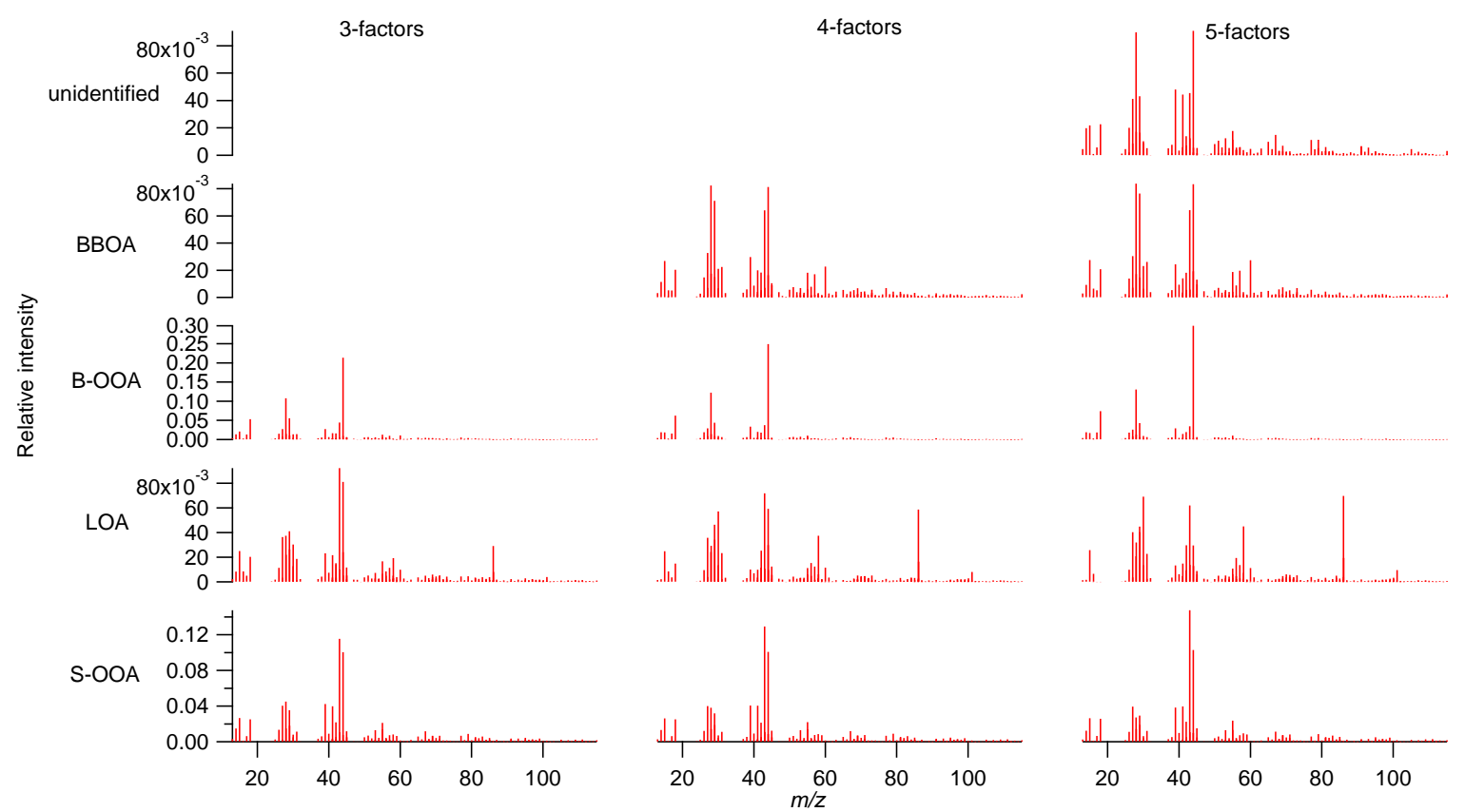

2 Figure S2. Offline-AMS source apportionment: water-soluble organic aerosol mass spectra of 3 the resolved PMF factors for the 3-, 4-, and 5-factor solutions. The BBOA factor is resolved 4 in the 4-factor solution. Another OOA factor is resolved in the 6-factor solution but could not 5 be associated to a specific aerosol source/process.

6
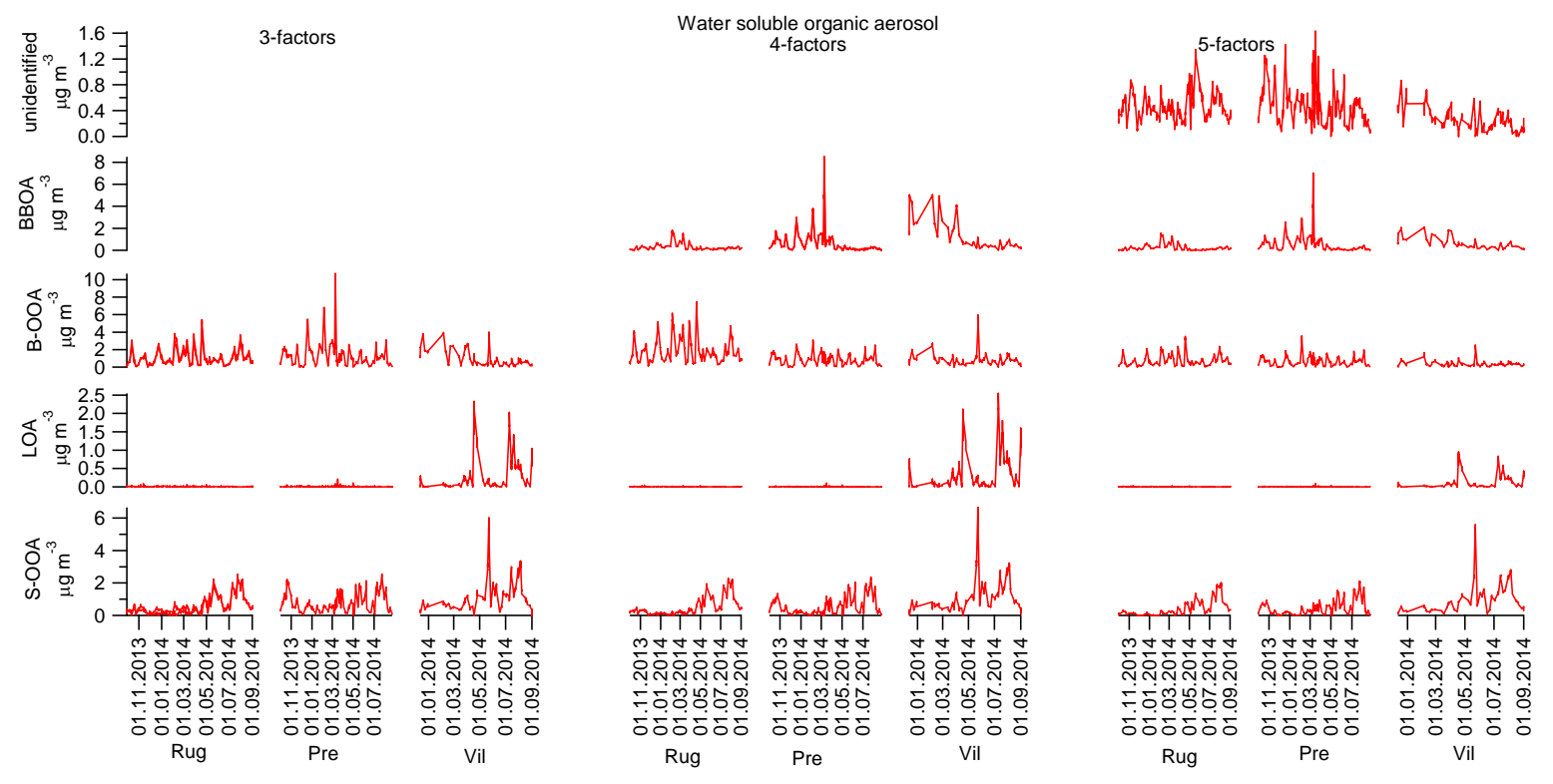

8 Figure S3. Offline-AMS source apportionment: water-soluble organic aerosol time series of

9 the resolved PMF factors for the 3-, 4-, and 5-factor solutions. The BBOA factor is resolved 10 in the 4- and 5- factor solution. 


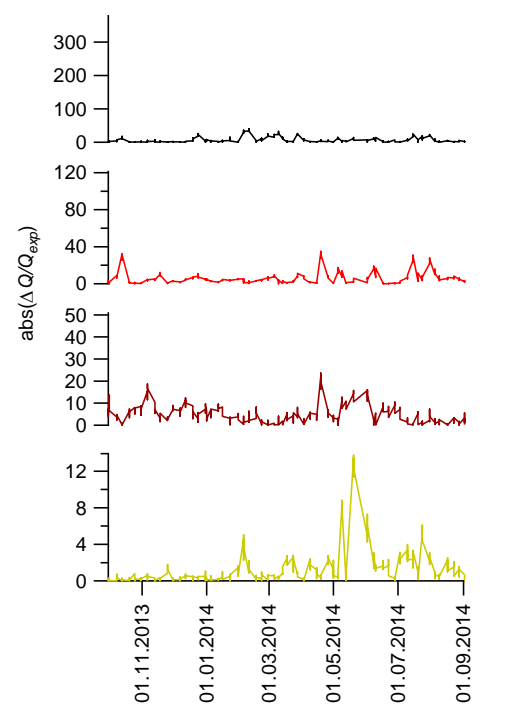

Rug

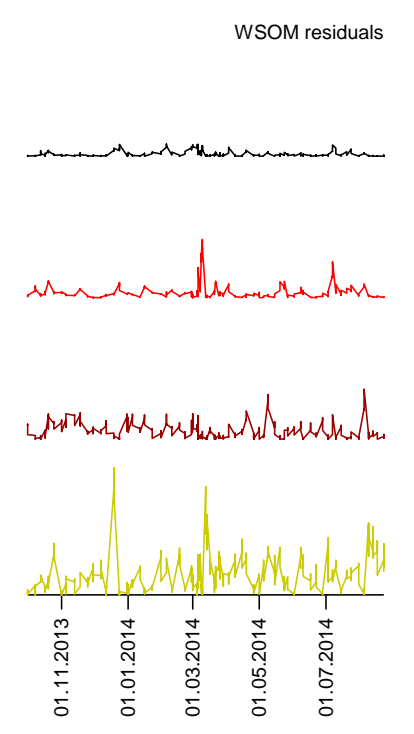

Pre
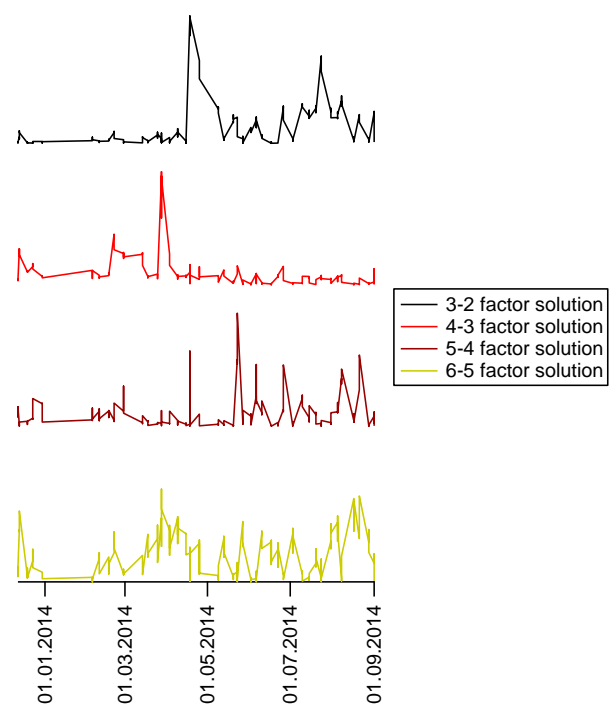

Vil

2 Figure S4. Offline-AMS PMF. $Q / Q_{\text {exp }}$ represents the ratio between the sum of the squares of

3 the residuals scaled by the uncertainty (Eq. 2) and $Q_{\text {exp }}$, which is and the remaining degrees of

4 freedom of the model solution $\left(Q_{e x p}\right)$ calculated as $i j-(j+i) p$ (Canonaco et al., 2013). Here,

$5 \operatorname{abs}\left(\Delta\left(Q / Q_{\text {exp }}\right)\right)$ denotes the absolute difference of $Q / Q_{\text {exp }}$ between different solution orders. A

6 strong decrease of the $Q / Q_{\text {exp }}$, passing from lower to higher order solutions indicates a better

7 explanation of the variability by the model. In this study, a large $Q / Q_{\text {exp }}$ decrease was

8 observed for Vilnius during summer when passing from 2 to 3 factors, with the separation of

9 the LOA factor. The 4-factor solution enabled resolving BBOA, with a decrease of $Q / Q_{\exp }$

10 observed mostly for Vilnius during winter, where the BBOA concentrations were high.

11 Increasing the number of factors provided further small contributions to the explained

12 variability, resulting in a separation of other OOA factors, which couldn't be associated to 13 aerosol sources or processes. 


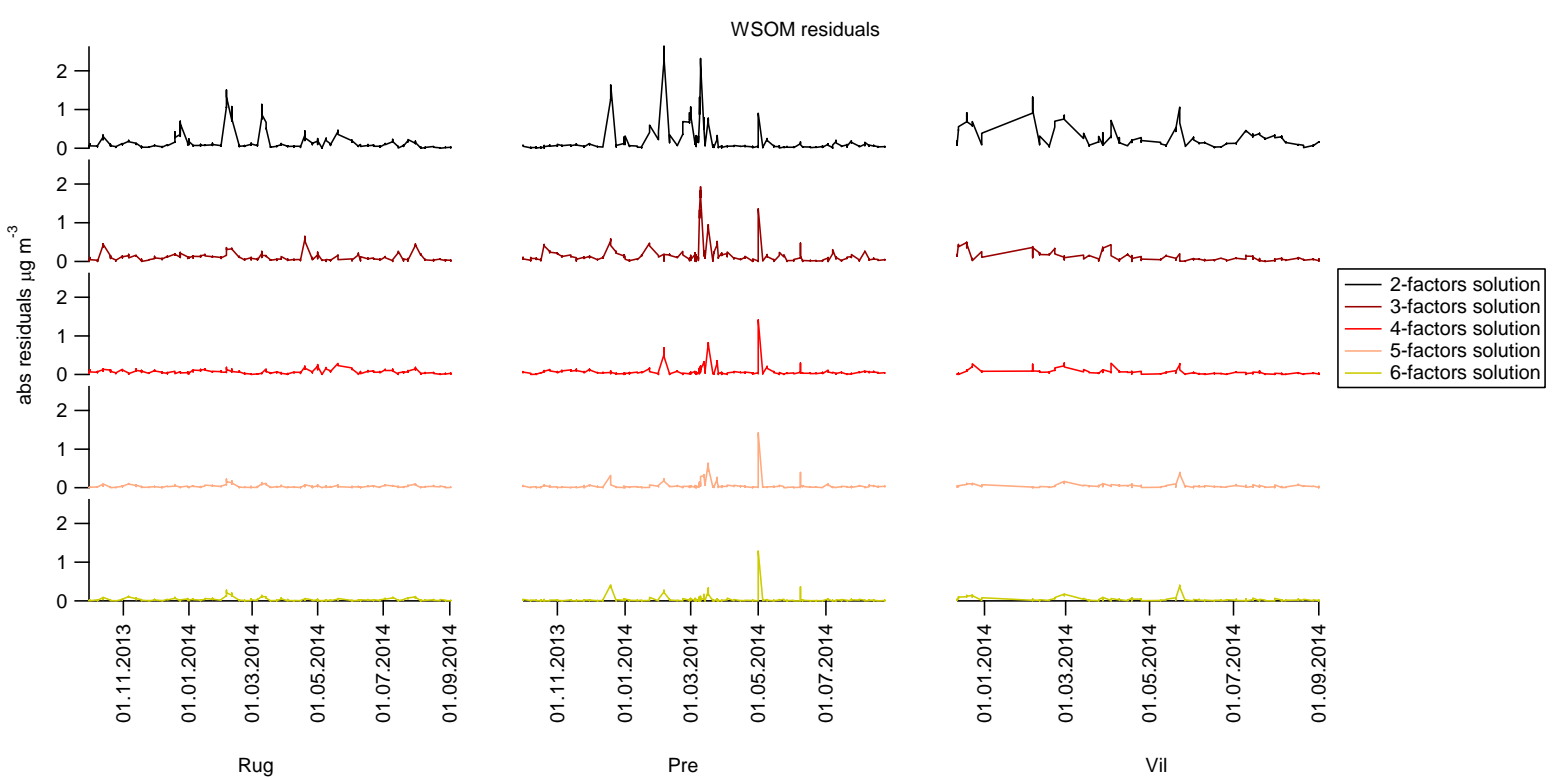

2 Figure S5. Offline-AMS PMF: WSOM absolute residuals for different number of factors.

3

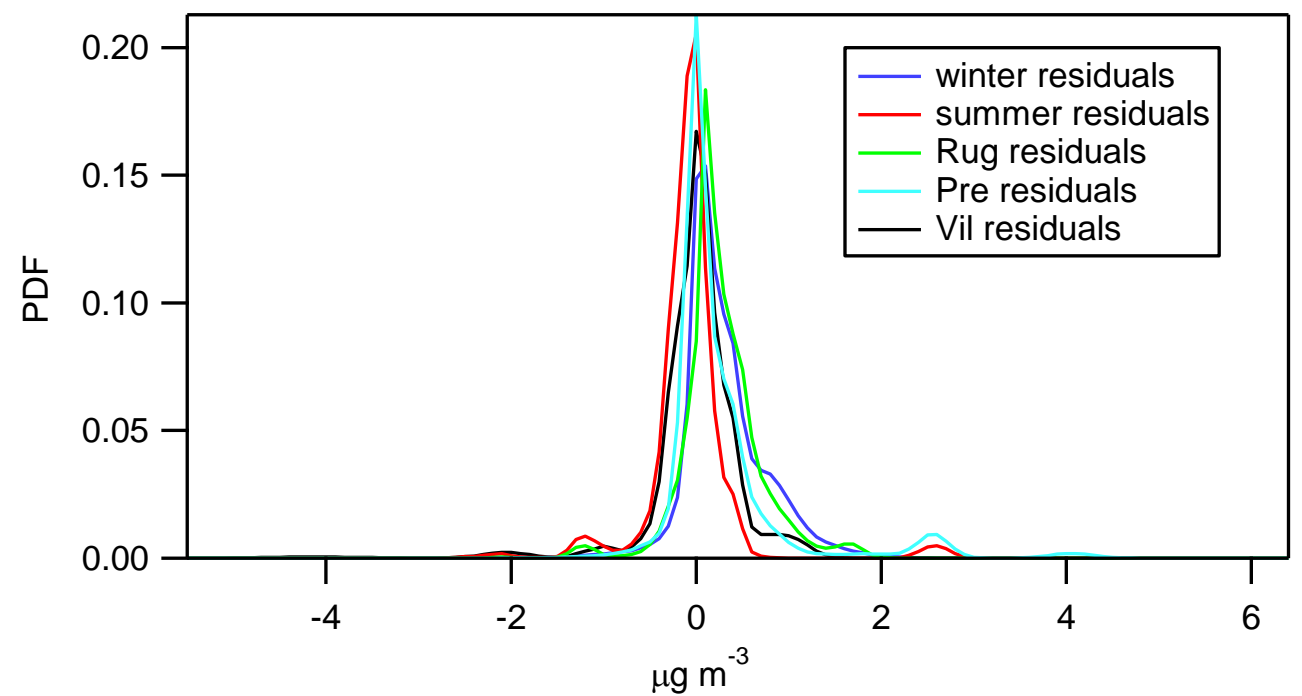

5 Figure S6. Probability density functions of the OC residuals from $R_{Z}$ sensitivity analysis (Eq.

6 6) for different stations and seasons from the accepted solutions (offline-AMS). 


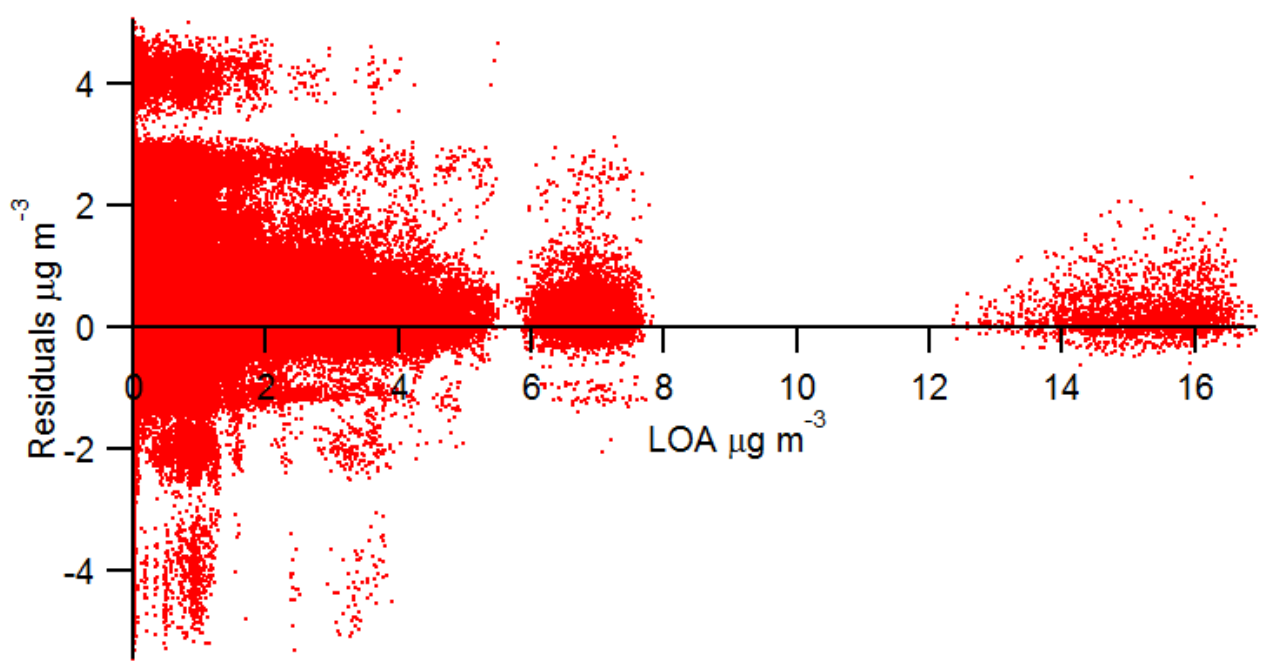

2 Figure S7. Scatterplot of OC residuals from $R_{Z}$ sensitivity analysis (Eq. 6) vs. LOA 3 concentration from the accepted solutions.

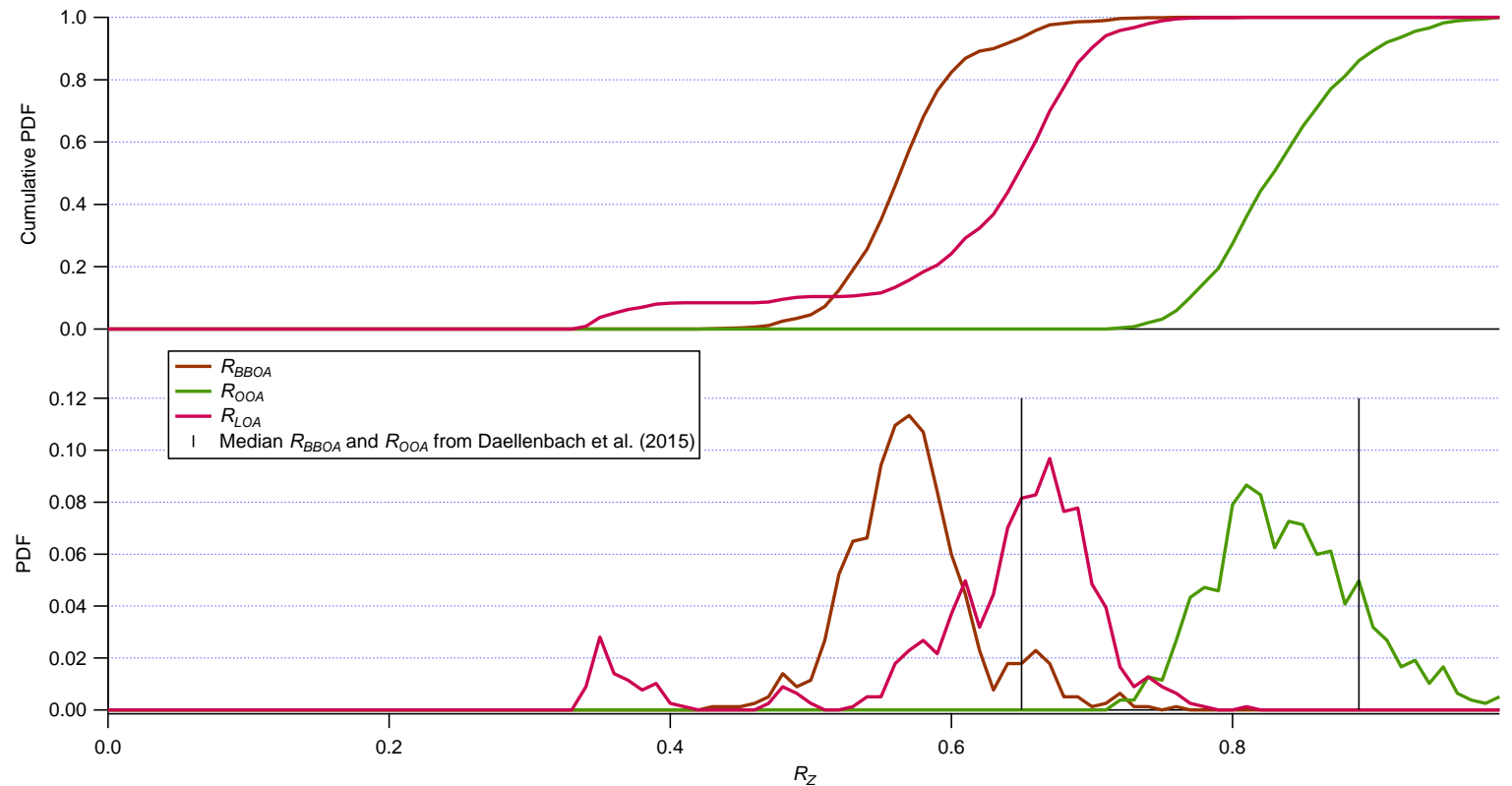

5 Figure S8. Factor recoveries: probability density functions. 
1 Table S2: Z-score table for offline-AMS factor contributions at different stations and seasons.

2 The $z$-score was calculated to determine whether the average factor contribution at one 3 station/season $\left(Z_{\text {avg }}\right)$ was statistically different from 0 .

4

$$
z \text {-score }=Z_{a v g} / \sigma_{z}
$$

5 where $\sigma_{z}$ denotes the uncertainty calculated according to the source apportionment error

6 model described in the manuscript $\left(\sigma_{S . A .}\right)$.

$7 \quad Z$-score values $<3$ are highlighted in pink.

\begin{tabular}{|c|c|c|c|c|c|c|}
\hline & & $\mathrm{BBOA}$ & LOA & B-OOA & S-OOA & TEOA \\
\hline \multirow{4}{*}{ Rug } & Fall & 13.6 & 1.8 & 17.7 & 8.1 & 6.1 \\
\hline & winter & 21.9 & 1.9 & 30.3 & 7.8 & 21.2 \\
\hline & spring & 9.9 & 1.9 & 22.3 & 15.2 & 4.3 \\
\hline & summer & 10.7 & 1.6 & 21.1 & 15.6 & 5.7 \\
\hline \multirow{4}{*}{ Pre } & Fall & 20.6 & 1.9 & 19.9 & 14.3 & 13.6 \\
\hline & winter & 21.1 & 2.3 & 22.2 & 8.7 & 346.7 \\
\hline & spring & 20.6 & 2.3 & 21.6 & 16.9 & 21.9 \\
\hline & summer & 11.5 & 1.7 & 15.6 & 17.1 & 2.8 \\
\hline \multirow{4}{*}{ Vil } & Fall & 13.4 & 1.3 & 5.3 & 5.5 & 23.9 \\
\hline & winter & 19.6 & 1.6 & 10.4 & 11.6 & 30.7 \\
\hline & spring & 19.3 & 2.2 & 9.2 & 5.6 & 36.4 \\
\hline & summer & 14.8 & 4.0 & 8.7 & 11.9 & 10.3 \\
\hline
\end{tabular}


1 Table S3: Z-score table for factor contributions at different stations and seasons (marker 2 source apportionment). Larger uncertainties in comparison to the offline-AMS source 3 apportionment could derive from the smaller amount of variables and measurements. *SA $=$ 4 secondary aerosol. $Z$-score values $<3$ are highlighted in pink.

\begin{tabular}{|c|c|c|c|c|c|c|c|c|}
\hline & & $\mathrm{SO}_{4}{ }^{2-}-\mathrm{SA}^{*}$ & MSA-SA* & $\mathrm{NO}_{3}{ }^{-}-\mathrm{SA}^{*}$ & BB & $\mathrm{TE}$ & PB & $\mathrm{Na}^{+}$-rich \\
\hline \multirow{4}{*}{ Rug } & Fall & 4.5 & 0.8 & 2.6 & 5.2 & 1.5 & 1.1 & 3.0 \\
\hline & Winter & 6.1 & 1.3 & 6.8 & 7.4 & 2.0 & 1.9 & 7.3 \\
\hline & Spring & 8.2 & 1.9 & 3.7 & 5.2 & 1.5 & 1.4 & 3.2 \\
\hline & Summer & 7.8 & 1.9 & 2.0 & 3.1 & 1.6 & 1.7 & 2.8 \\
\hline \multirow{4}{*}{ Pre } & Fall & 6.7 & 1.5 & 3.6 & 4.5 & 1.4 & 1.8 & 5.9 \\
\hline & Winter & 4.9 & 1.1 & 4.5 & 5.9 & 1.5 & 1.4 & 4.2 \\
\hline & Spring & 6.1 & 3.2 & 0.9 & 3.0 & 1.2 & 1.4 & 6.1 \\
\hline & Summer & 8.9 & 3.6 & 1.5 & 0.6 & 1.8 & 1.9 & 5.9 \\
\hline \multirow{4}{*}{ Vil } & Fall & 0.9 & 1.6 & 3.9 & 2.6 & 0.6 & 0.7 & 4.8 \\
\hline & Winter & 5.6 & 0.8 & 5.6 & 4.6 & 1.2 & 1.2 & 4.2 \\
\hline & Spring & 6.7 & 1.0 & 0.7 & 0.8 & 0.5 & 2.1 & 1.1 \\
\hline & Summer & - & - & - & & & & - \\
\hline
\end{tabular}




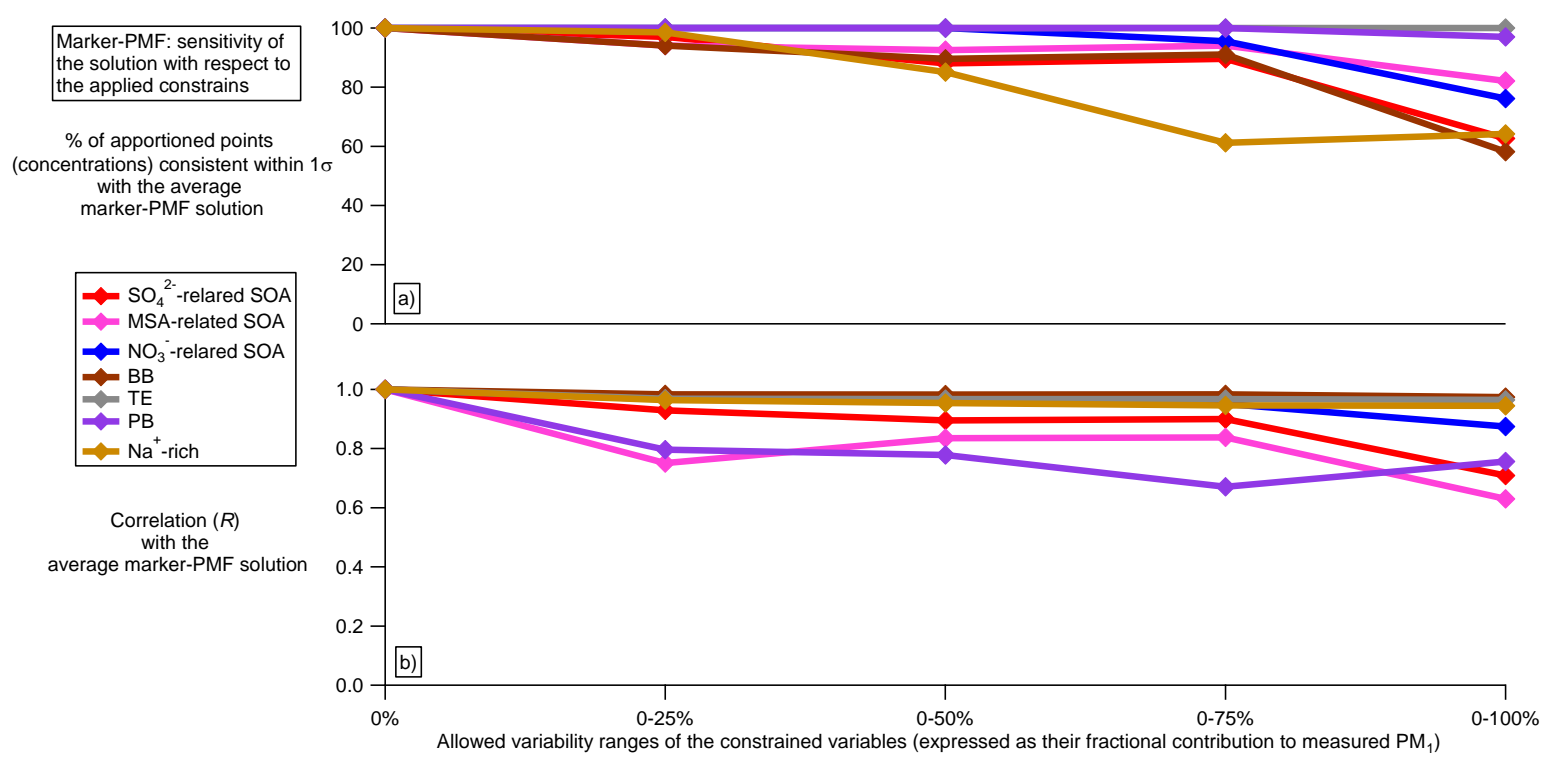

Figure S9. Marker-PMF sensitivity analysis of the applied constraints. Constraints assuming 3 variables to be equal 0 were loosened allowing each of these variables to vary within a certain 4 range of its average relative contribution to measured $\mathrm{PM}_{1} .0 \%$ denotes the fully constrained 5 solution, corresponding to the average bootstrap marker-PMF source apportionment.

6

7

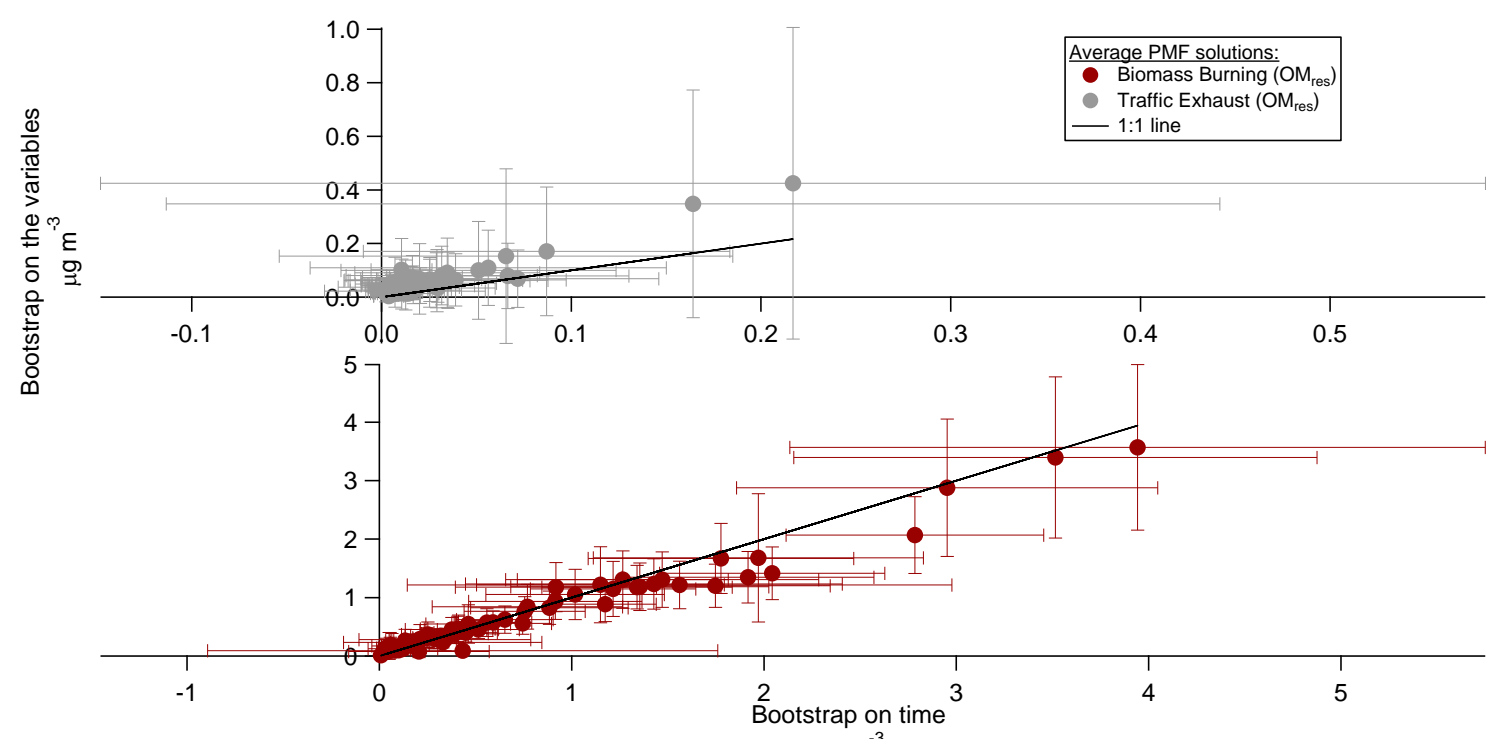
$\mu \mathrm{g} \mathrm{m}^{-3}$

9 Figure S10. Marker-PMF sensitivity analysis: comparison between the apportionment of $10 \mathrm{OM}_{\mathrm{res}}$ in $\mathrm{BB}$ and TE obtained bootstrapping time points (x-axes) and variables (y-axes). 


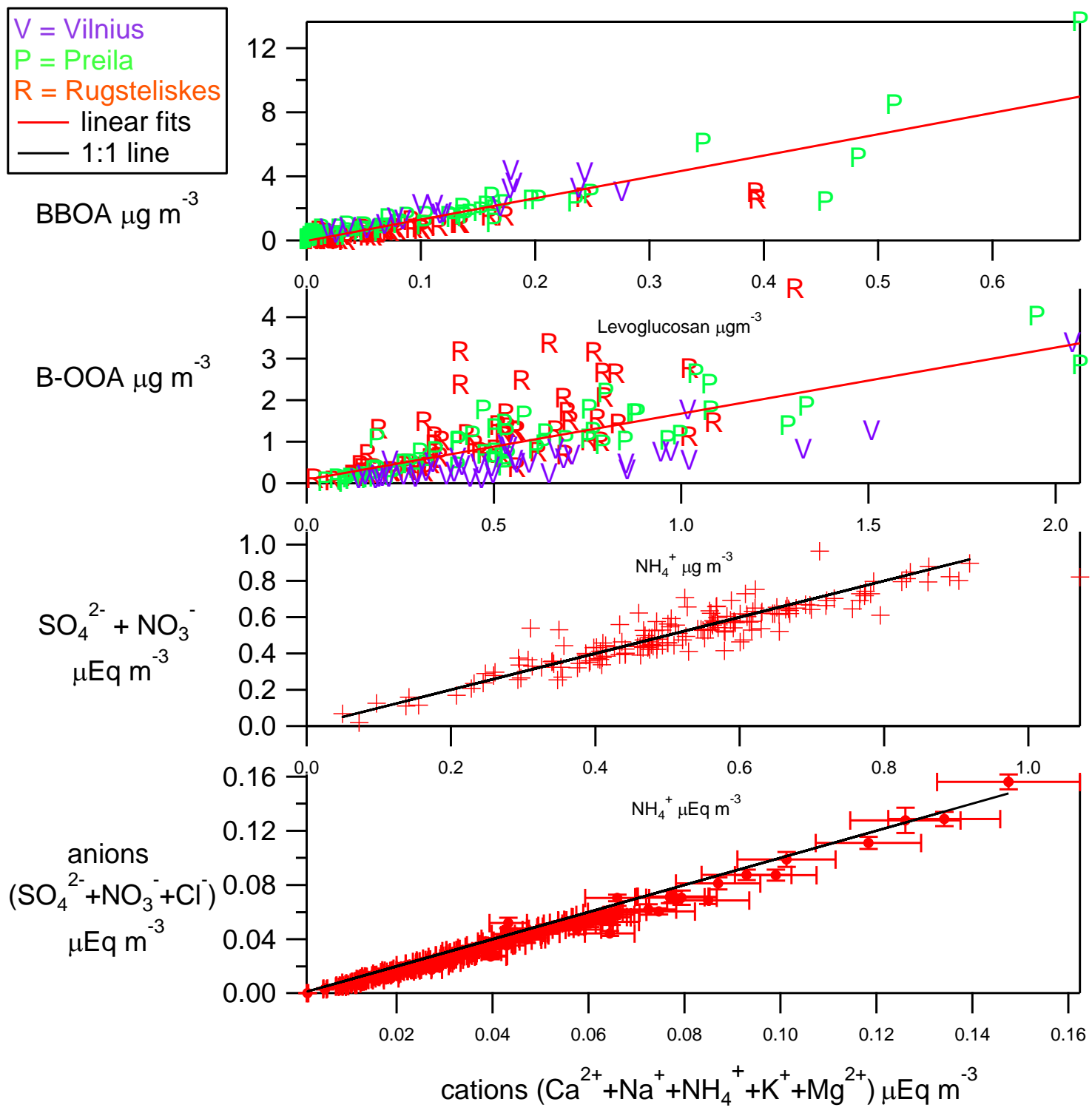

3 Figure S11. Scatter plots of BBOA vs. Levoglucosan (top), B-OOA vs. $\mathrm{NH}_{4}^{+}, \mathrm{NH}_{4}{ }^{+}$vs. the 4 sum of $\mathrm{SO}_{4}{ }^{2-}$ and $\mathrm{NO}_{3}{ }^{-}\left[\mu \mathrm{Eq} \mathrm{m}{ }^{-3}\right]$ (IC data), and ion balance (bottom). The B-OOA factor 5 correlation with $\mathrm{NH}_{4}{ }^{+}$is significant at all stations: $R=0.82\left(R^{2}=0.67\right)$ for Vilnius, $0.87\left(R^{2}=\right.$ $60.76)$ for Preila, and $0.71\left(R^{2}=0.50\right)$ for Rūgšteliškis. The correlation of B-OOA with a 7 secondary inorganic component such as $\mathrm{NH}_{4}{ }^{+}$could suggest the secondary origin of B-OOA, 8 as also inferred by the comparison with the marker-source apportionment (section 4.4.2). The 9 repeatability of $\mathrm{NH}_{4}{ }^{+}$IC measurements was $10 \%$, while according to our error estimate 10 (Section 3.1.3), the average relative uncertainty on the B-OOA factor for Rūgšteliškis was $1112 \%$. Considering these two error sources and assuming an initial perfect correlation between $12 \mathrm{NH}_{4}{ }^{+}$and B-OOA, we estimated that the unexplained variability of the correlation due to our 
1 uncertainty can be up to $23 \%$ in Rūgšteliškis. These findings suggest that while for Preila and

2 Vilnius the B-OOA vs $\mathrm{NH}_{4}{ }^{+}$unperfected correlation can be explained by our uncertainty, for 3 Rūgšteliškis the remaining unexplained variability (27\%) can be related to a different 4 secondary precursor composition and/or different photochemical aging of the air parcel in 5 comparison to the other stations.

6
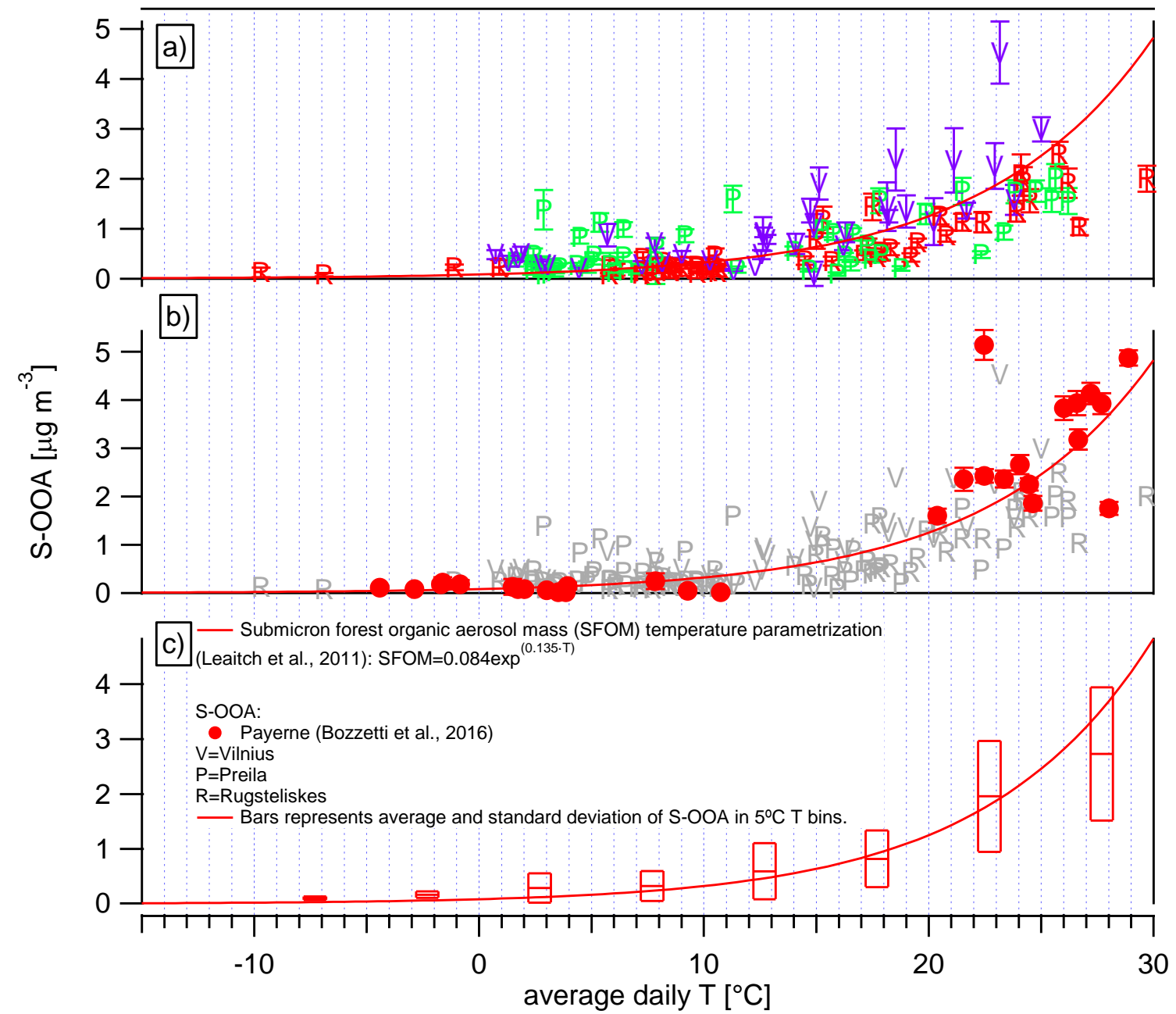

8 Figure S12. S-OOA temperature dependence and submicron forest organic aerosol mass

9 (SFOM) temperature parameterization by Leaitch et al. (2015). a) Lithuania; b) rural site of

10 Payerne (Switzerland), Bozzetti et al. (2016); c) binned S-OOA concentrations (average and 11 standard deviation). 


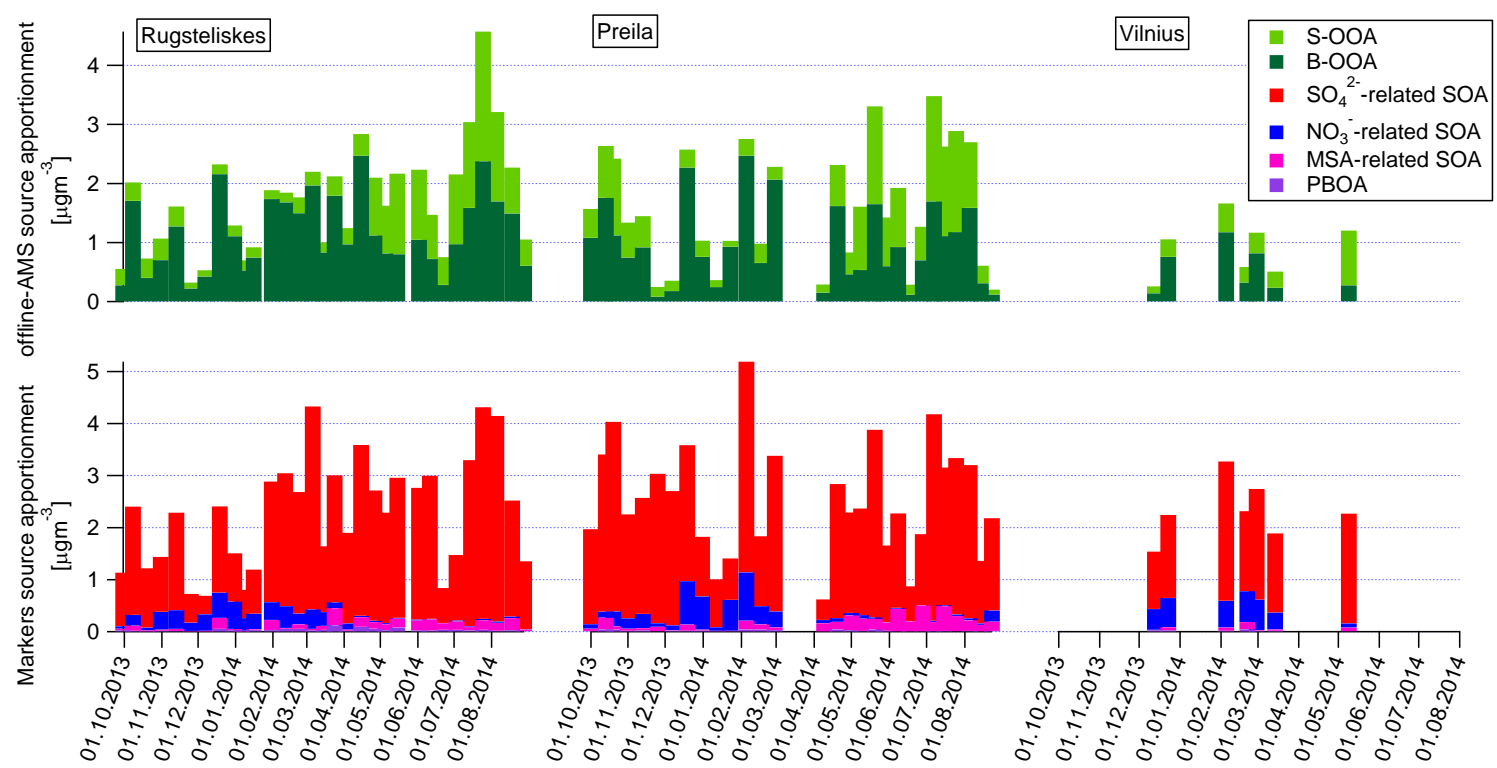

1

2 Figure $\mathrm{S} 13$. Other-OA $\mathrm{A}_{\text {offline-AMS }}$ and Other-OA $\mathrm{A}_{\text {marker }}$ time series. Results represent the average 3 PMF solutions.
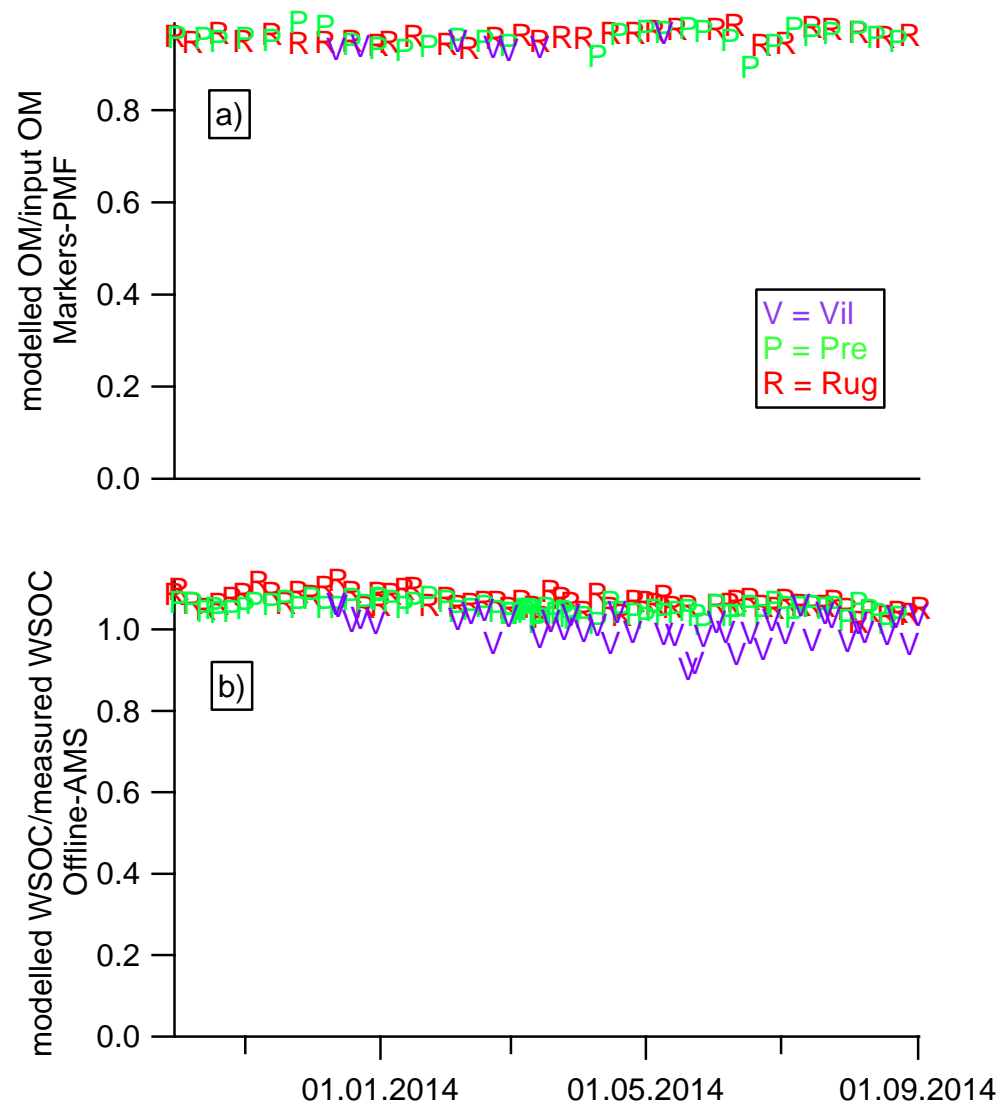

5 Figure S14. a) Modelled OM : input OM for the markers-PMF. b) Modelled WSOC : 6 measured WSOC for the offline-AMS PMF 


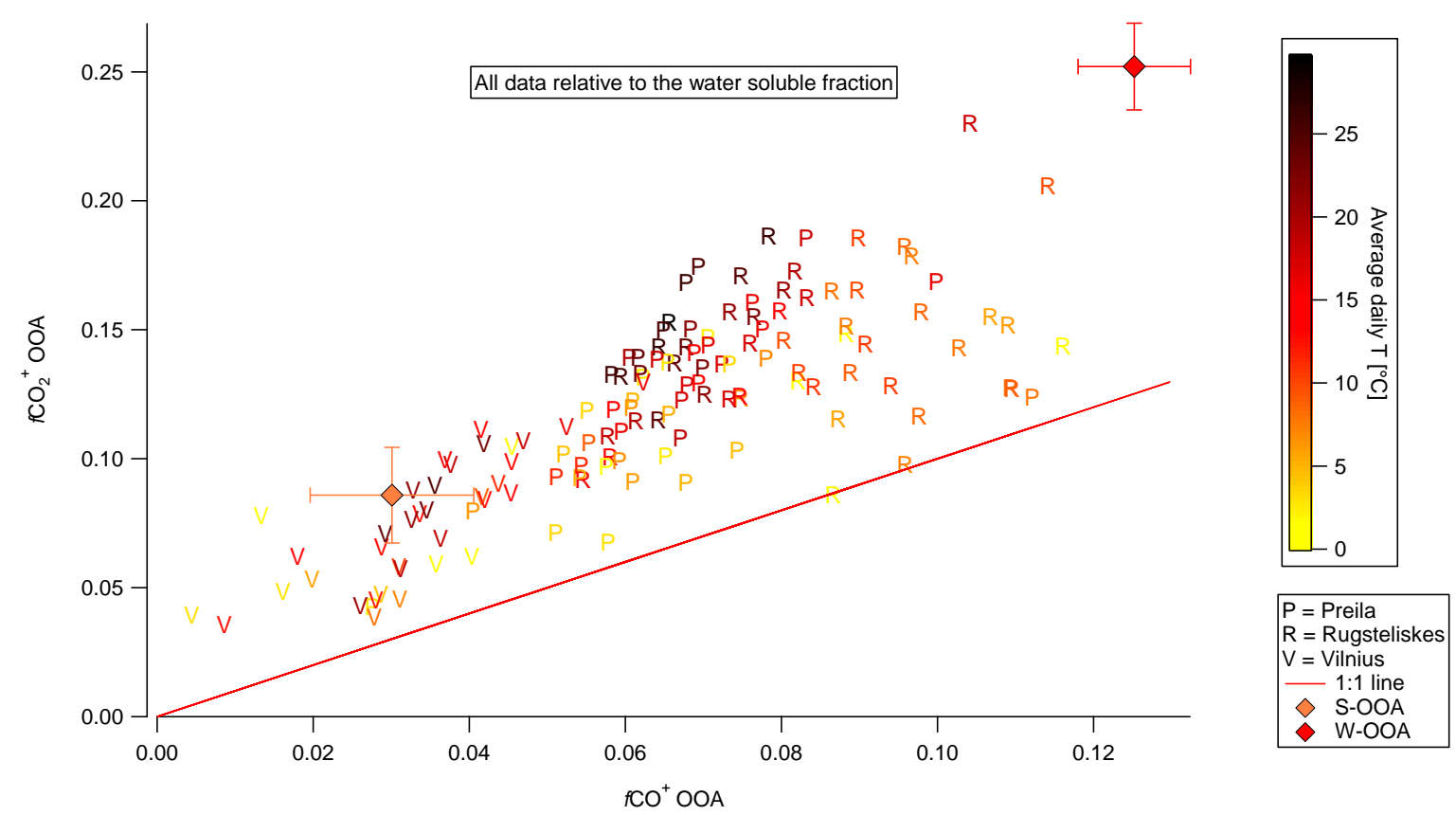

2 Figure S15. Scatter plot of $f \mathrm{CO}_{2}^{+}$vs. $f \mathrm{CO}^{+}$only from water-soluble OOA. The OOA 3 contribution to $f \mathrm{CO}^{+}$and $f \mathrm{CO}_{2}{ }^{+}$was estimated by subtracting the non-OOA $f \mathrm{CO}^{+}$and $f \mathrm{CO}_{2}{ }^{+}$ 4 contributions from the measured $f \mathrm{CO}^{+}$and $f \mathrm{CO}_{2}{ }^{+}$. The color code denotes the average daily 5 temperature $\left[{ }^{\circ} \mathrm{C}\right]$, diamonds indicate the $\mathrm{CO}_{2}{ }^{+}: \mathrm{CO}^{+}$ratio for different PMF factor profiles.

\section{$6 \mathrm{CO}^{+}$parameterization (3-parameter fit)}

7 We fitted the measured water-soluble $\mathrm{CO}^{+}$variability as a function of the measured water8 soluble $\mathrm{CO}_{2}{ }^{+}, \mathrm{C}_{2} \mathrm{H}_{4} \mathrm{O}_{2}{ }^{+}$, and $\mathrm{C}_{2} \mathrm{H}_{3} \mathrm{O}^{+}$. The multilinear fit returned $0.56,1.30$ and -0.18 as coefficients for $\mathrm{CO}_{2}^{+}, \mathrm{C}_{2} \mathrm{H}_{4} \mathrm{O}_{2}^{+}$, and $\mathrm{C}_{2} \mathrm{H}_{3} \mathrm{O}^{+}$, respectively. In order to ensure positive contributions from the separated aerosol sources to $\mathrm{CO}^{+}$, we parameterized the $\mathrm{CO}^{+}$ variability as the sum of the $\mathrm{CO}^{+}$contributions explained by BBOA and S-OOA and B-OOA, which together represented $97 \%$ of the $\mathrm{CO}^{+}$explained variability (BBOA 20\%, S-OOA 12\%, 13 B-OOA 65\%):

$$
\mathrm{CO}^{+}{ }_{i}=\mathrm{CO}_{\mathrm{S}-\mathrm{OOA}, i}^{+}+\mathrm{CO}^{+}{ }_{\mathrm{B}-\mathrm{OOA}, i}+\mathrm{CO}^{+}{ }_{\mathrm{BBOA}, i}
$$

The $\mathrm{CO}^{+}{ }_{i}$ parameterization as a function of the $\mathrm{CO}^{+}$fraction explained by the PMF factors ensures positive contributions from all terms.

The $\mathrm{CO}_{S-O O A, i}^{+}, \mathrm{CO}_{B-O O A, i}^{+}$, and $\mathrm{CO}_{B B O A, i}^{+}$terms can be written as functions of $\mathrm{CO}_{2}{ }^{+}, \mathrm{C}_{2} \mathrm{H}_{3} \mathrm{O}^{+}$, and $\mathrm{C}_{2} \mathrm{H}_{4} \mathrm{O}_{2}^{+}$, chosen as S-OOA, B-OOA, and BBOA tracers.

$$
\mathrm{CO}^{+}{ }_{S-O O A, i}=\left(\frac{f C O^{+}}{f_{2} \mathrm{H}_{3} O^{+}}\right)_{S-O O A} \cdot C_{2} H_{3} O^{+}{ }_{S-O O A, i}
$$




$$
\mathrm{CO}_{B-O O A, i}^{+}=\left(\frac{f C O^{+}}{f C O_{2}^{+}}\right)_{B-O O A} \cdot \mathrm{CO}_{2}^{+}{ }_{B-O O A, i}
$$

$$
\mathrm{CO}_{B B O A, i}^{+}=\left(\frac{f C O^{+}}{f_{2} \mathrm{H}_{4} \mathrm{O}_{2}^{+}}\right)_{B B O A} \cdot \mathrm{C}_{2} \mathrm{H}_{4} \mathrm{O}_{2}^{+}{ }_{B B O A, i}
$$

3 Therefore Eq. (S3) can be expressed as:

$$
\mathrm{CO}^{+}{ }_{i}=\left(\frac{f C O^{+}}{f C_{2} \mathrm{H}_{3} \mathrm{O}^{+}}\right)_{S-O O A} \cdot C_{2} \mathrm{H}_{3} O^{+}{ }_{S-O O A, i}+C O_{B-O O A, i}^{+}+\left(\frac{f C O^{+}}{f C O_{2}^{+}}\right)_{B-O O A} \cdot C O_{2}^{+}{ }_{B-O O A, i}+C O_{B B O A, i}^{+}+\left(\frac{f C O^{+}}{f C_{2} H_{4} O_{2}^{+}}\right)_{B B O A} \cdot C_{2} H_{4} O_{2}^{+}{ }_{B B O A, i}
$$

Algebraic expressions for the pre-factors $a, b$, and $c$ are given in Eq. (S11), (S12) and (S13). These coefficients were estimated as equal to $0.51,1.50$, and -0.10 , respectively.

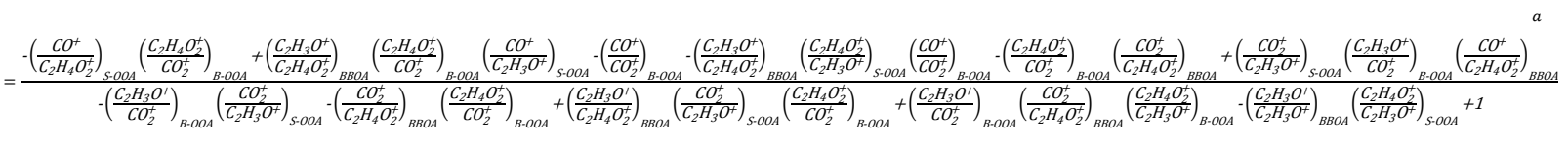

By substituting Eq. (S9), Eq. (S10), and Eq. (S11) into Eq. (S7) and grouping the $\mathrm{CO}_{2}^{+}$, $\mathrm{C}_{2} \mathrm{H}_{4} \mathrm{O}_{2}{ }^{+}$, and $\mathrm{C}_{2} \mathrm{H}_{3} \mathrm{O}^{+}$multiplication coefficients, we can express the $\mathrm{CO}^{+}{ }_{i}$ variability as function of the $\mathrm{C}_{2} \mathrm{H}_{3} \mathrm{O}^{+}, \mathrm{C}_{2} \mathrm{H}_{4} \mathrm{O}_{2}{ }^{+}$, and $\mathrm{CO}_{2}{ }^{+}$fragments as:

$$
\mathrm{CO}^{+}{ }_{i}=a \cdot \mathrm{CO}_{2}{ }_{i}+b \cdot \mathrm{C}_{2} \mathrm{H}_{4} \mathrm{O}_{2}{ }^{+}{ }_{i}+c \cdot \mathrm{C}_{2} \mathrm{H}_{3} \mathrm{O}^{+}{ }_{i}
$$

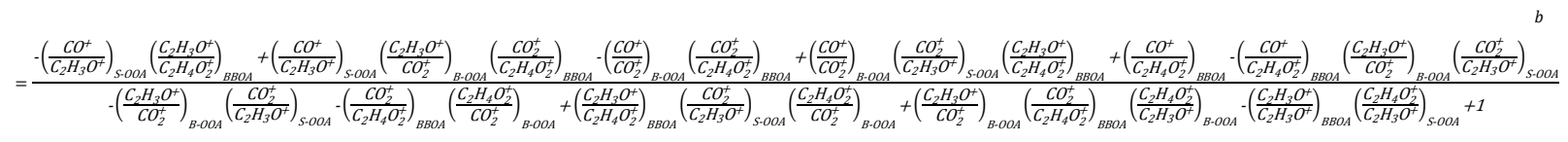

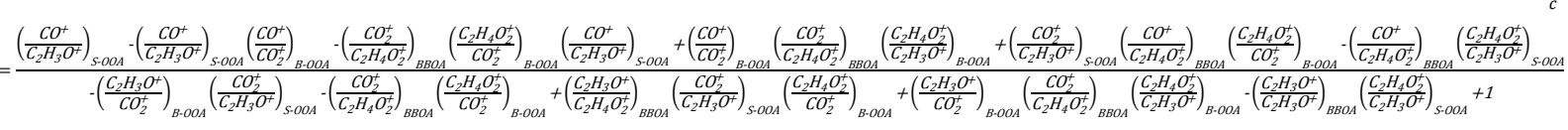

20 Limitations of this parameterization could arise in case of dominating COA contributions,

21 such as in direct emission studies, as the typical AMS fingerprint associated to this source 
1 shows high $f \mathrm{C}_{2} \mathrm{H}_{3} \mathrm{O}^{+}$and low $f \mathrm{CO}_{2}{ }^{+}$and $f \mathrm{C}_{2} \mathrm{H}_{4} \mathrm{O}_{2}{ }^{+}$contributions, leading to a possible 2 negative $f \mathrm{CO}^{+}$estimate.

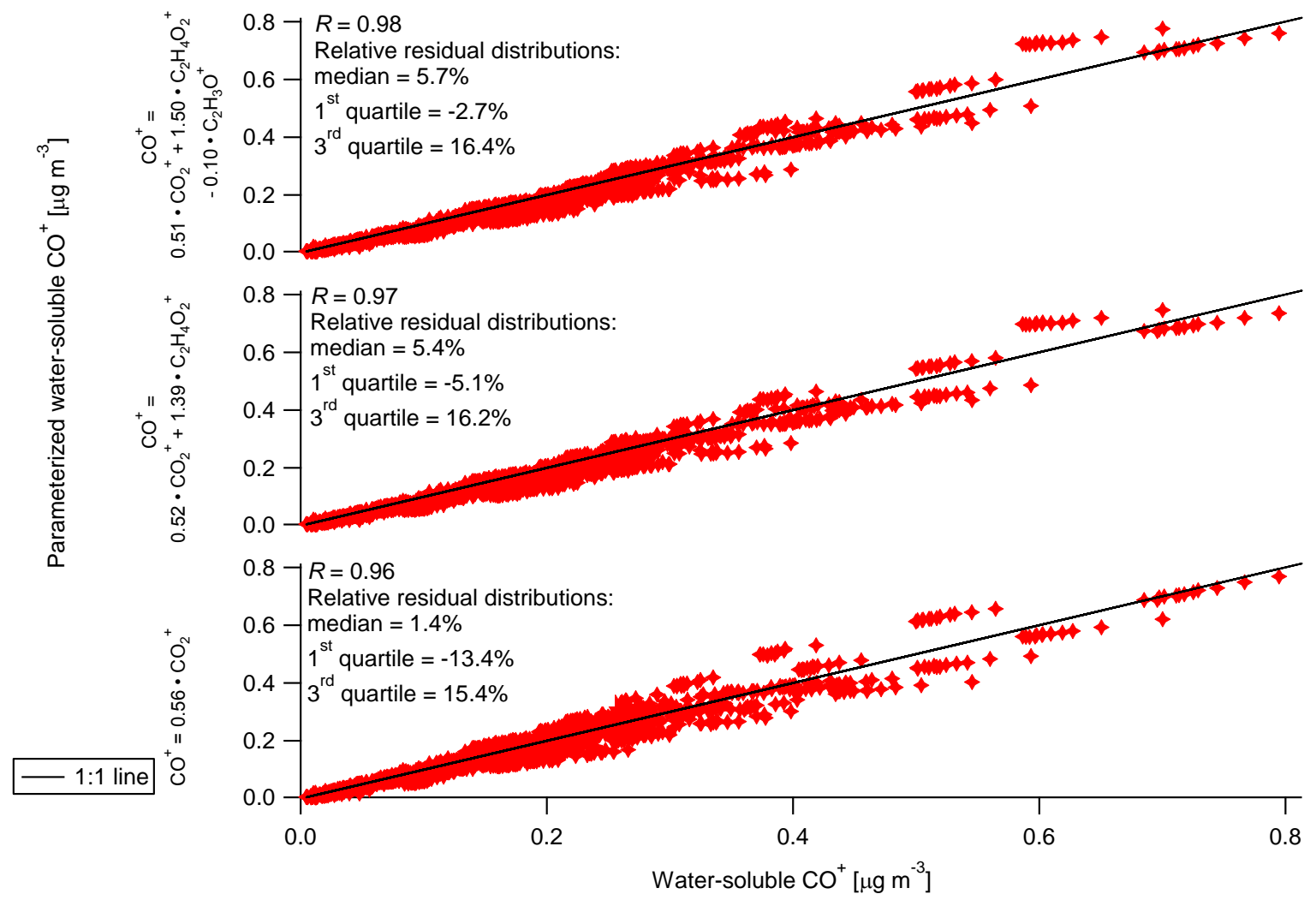

Figure $\mathrm{S} 16 . \mathrm{CO}^{+}$parameterization residuals: 1, 2, and 3-parameters fit.

5 We recalculated the OM:OC ratio for the water soluble collected spectra according to the new parametrization reported by Canagaratna et al. (2015). Consistently with what reported in Canagaratna et al. (2015), the newly calculated OM:OC ratio was on average 9\% higher than the OM:OC ratio calculated according to the Aiken method (Aiken et al., 2008). More specifically, the OM:OC ratio was on average 9\% higher during summer, and $10 \%$ during winter. The two methods reported well correlating OM:OC values $(R=0.98$ over the whole monitoring period, $R=0.99$ during winter, $R=0.97$ during summer). In our study, the OM:OC ratios of our water soluble mass spectra were mostly used to determine the total WSOM concentrations. Considering the high correlations between the Aiken and Canagaratna OM:OC ratios, we can exclude large effects due to the different parameterizations on the WSOM variability and therefore on the source apportionment. Moreover, the recovery estimates are independent of the choice of Aiken or Canagaratna's OM:OC parameterizations. Indeed the recovery fitting equation (Eq. 6) explicitly contains the PMF factors' OM:OC ratios. However, the water-soluble PMF factor concentrations in Eq. 6 implicitly depend on the bulk OM:OC ratio used to determine the bulk WSOM concentration $\left(\mathrm{WSOM}_{i}=\right.$ 
$1 \mathrm{WSOC}_{i} \cdot \mathrm{OM}: \mathrm{OC}_{i}$ ) which was used as input for our PMF model. This leads to canceling

2 corrections making the recovery estimates independent of the choice of the Aiken's or

3 Canagaratna's OM:OC parameterizations. Nevertheless the WSOM estimated concentrations

4 are $10 \%_{\text {avg }}$ larger, when assuming the Canagaratna OM:OC parametrization. In general Aiken

5 assumed a $\mathrm{CO}_{2}^{+}: \mathrm{CO}^{+}$ratio of 1 , while Canagaratna stated that such an assumption would

6 underestimate $\mathrm{CO}^{+}$. From our dataset, we observed a $\mathrm{CO}_{2}^{+}: \mathrm{CO}^{+}$of $1.75_{\text {med }}$ suggesting that the

7 Aiken OM:OC parametrization would represent more accurately our data although both

8 parametrizations are uncertain for this dataset.

9

10 Offline-AMS comparison with IC and WSOC determination by TOC analyzer.

11 Overall, the comparison between offline-AMS and IC concentrations of $\mathrm{NH}_{4}{ }^{+}, \mathrm{SO}_{4}{ }^{2-}$, and $12 \mathrm{NO}_{3}{ }^{-}$reveals a non-linear relation due to the lower IC detection limits. This is most likely 13 related to the low transmission efficiency of the AMS lens for small particles, particularly 14 predominant for diluted filter extracts.

15 Nevertheless, considering internally mixed nebulized particles, the composition of the 16 particles is not supposed to change with the solution concentration, as also confirmed by 17 dilution tests conducted on our filter extracts (Fig. S17). 

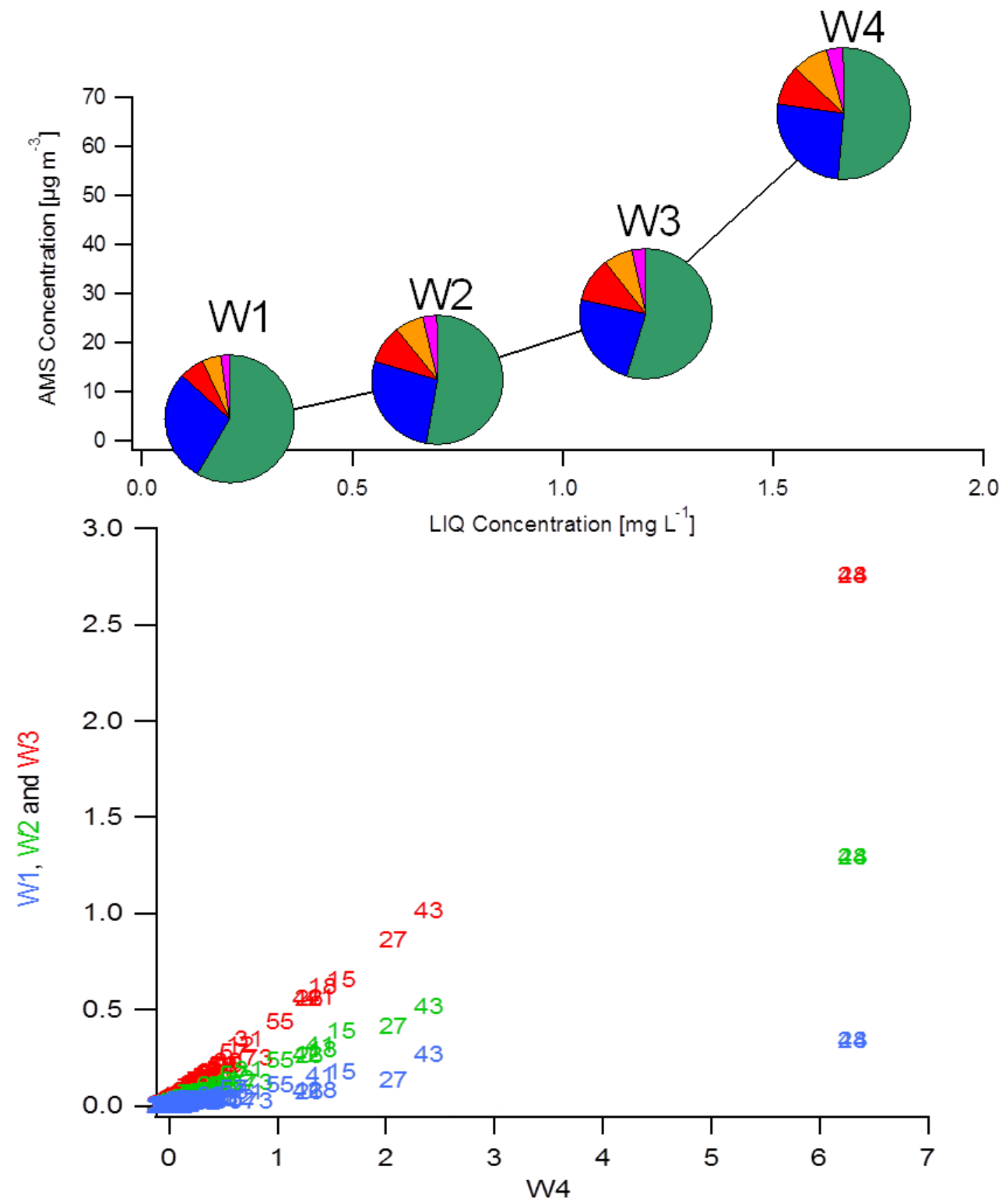

2 Figure S17. Dilution tests: NR PM composition and comparison of mass spectra registered at 3 different dilutions.

4 

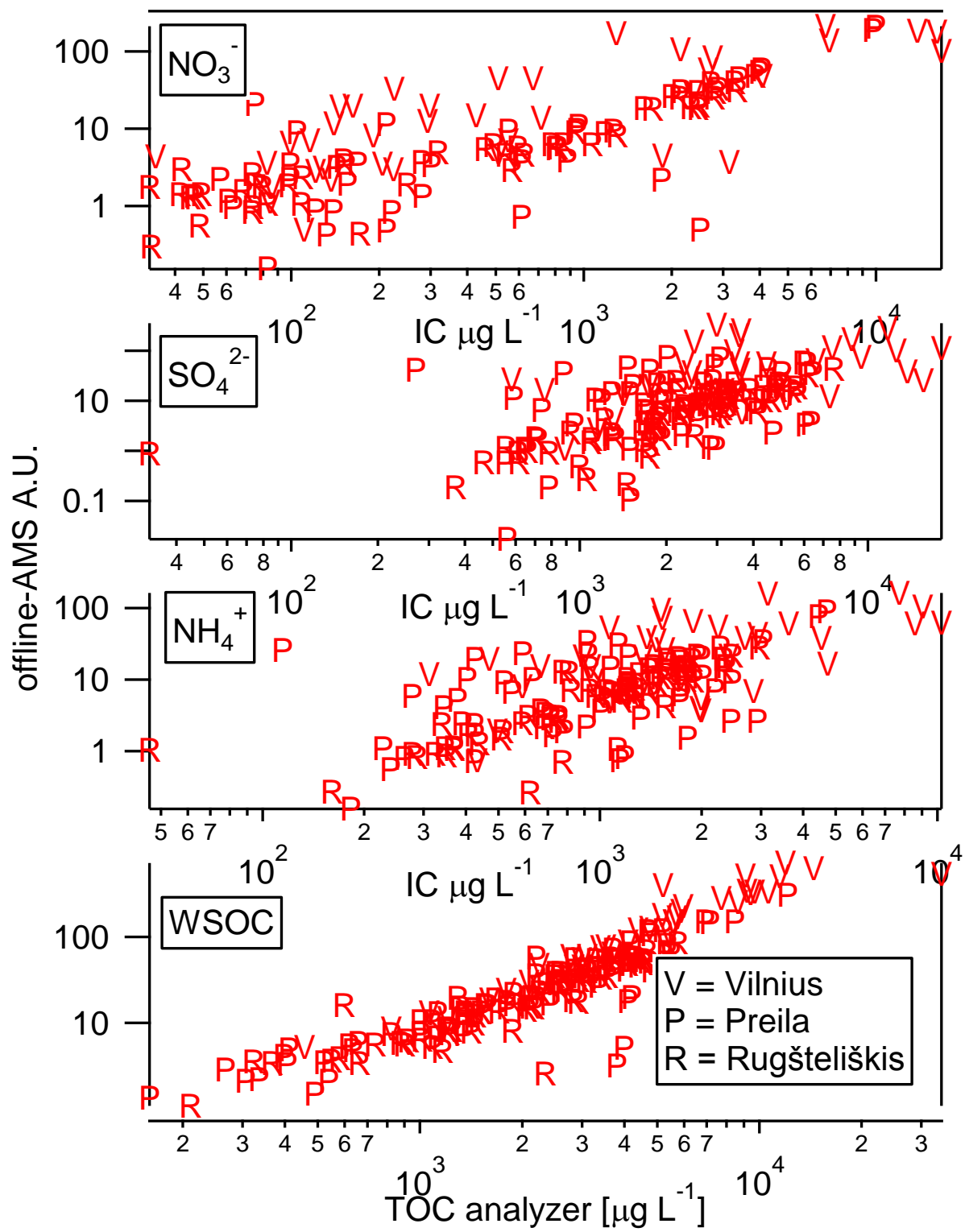

2 Figure S18. Offline-AMS comparison with IC and WSOC measurements by TOC analyzer.

3 The low particle transmission efficiency observed for diluted solutions results in a large

4 scattering at low concentration. Additional scattering is observed in the relation between

5 offline-AMS and IC for $\mathrm{SO}_{4}{ }^{2-}$. This is related to the presence of refractory sulfate salts (e.g.

$6 \mathrm{Na}_{2} \mathrm{SO}_{4}$ ) which are detectable by IC, but not by the AMS, consistent with lower slope

7 obtained between offline-AMS and $\mathrm{IC} \mathrm{SO}_{4}{ }^{2-}$, compared to the other species. These species are

8 likely formed during nebulization, e.g.

$9 \quad\left(\mathrm{NH}_{4}\right)_{2} \mathrm{SO}_{4}+\mathrm{CaCl}_{2} \rightleftharpoons \mathrm{CaSO}_{4}+2 \mathrm{NH}_{4} \mathrm{Cl}$

10 For these reasons we only reported inorganic ion concentrations from IC. 